\title{
Coping skills training was effective in adolescents with type 1 diabetes
}

Grey M, Boland EA, Davidson M, et al. Coping skills training for youths with diabetes on intensive therapy. Appl Nurs Res 1999 $\mathrm{Feb} ; 12: 3-12$.

\section{Question}

In adolescents with type 1 diabetes mellitus, does the addition of a behavioural programme of coping skills training (CST) to intensive diabetes management improve metabolic and psychosocial outcomes?

\section{Design}

Randomised, blinded (clinicians and outcome assessors), controlled trial with 6 months of follow up.

\section{Setting}

The Yale Pediatric Diabetes Service in New Haven, Connecticut, USA.

\section{Patients}

77 adolescents who were 13-20 years of age (mean age $16 \mathrm{y}$, $58 \%$ girls), had type 1 diabetes (mean duration 8.4 y) with no other health problems except for treated hypothyroidism, had been treated with insulin for $\geq 1$ year, had haemoglobin $A_{1 c}$ $\left(\mathrm{HbA}_{1 c}\right)$ concentration of $7-14 \%$, had no severe hypoglycaemic events in the previous 6 months, and were in an appropriate school grade for their age (within 1 year). Follow up was 100\%.

\section{Intervention}

Adolescents were allocated to intensive management plus CST $(\mathrm{n}=42)$ or intensive management alone $(\mathrm{n}=35)$. Intensive management consisted of $\geq 3$ daily insulin injections or an external insulin pump, self monitoring of blood glucose $\geq 4$ times daily, monthly outpatient visits, and interim telephone contacts. CST was given in small groups of 2-3 adolescents who were of similar age. CST sessions were 1-1.5 hours in duration, and adolescents attended 4-8 initial weekly sessions and subsequent monthly booster sessions.

\section{Main outcome measures}

$\mathrm{HbA}_{1 \mathrm{c}}$ concentration, hypoglycaemic events, clinically significant weight gain, self efficacy (Self-Efficacy for Diabetes Scale [SEDS]), depression (Children's Depression Inventory), and quality of life (Diabetes Quality of Life Scale).

\section{Main results}

$\mathrm{HbA}_{1 \mathrm{c}}$ concentrations decreased in both groups after 6 months; the decrease was greater for CST than for intensive management alone $\left(\mathrm{HbA}_{1 \mathrm{c}}\right.$ concentration decrease $7.8 \%$ v $8.3 \%$, $\mathrm{p}=0.02$ ). Hypoglycaemic events were similar in both groups (23 v 22 episodes for CST and intensive management alone, respectively; $p=0.6$ ). The groups did not differ in the number of adolescents who were overweight after 6 months. General self efficacy was greater in the CST group than in the intensive management alone group at 6 months (mean SEDS score $28.9 v$ $26.1, \mathrm{p}=0.01$ ). CST led to greater improvement on some of the quality of life subscales than did intensive management alone (mean score difference for disease impact 6.3 v $2.5, \mathrm{p}=0.01$; mean score difference for worry $3.3 v 0.1, \mathrm{p}=0.02)$. No differences between groups existed for depression.

\section{Conclusions}

In adolescents with type 1 diabetes mellitus, the addition of a coping skills training programme to intensive diabetes management led to improvement in haemoglobin $\mathrm{A}_{1 \mathrm{c}}$ concentration, general self efficacy, and some quality of life measures. Coping skills training did not reduce hypoglycaemic events or clinically significant weight.

Sources of funding: National Institute for Nursing Research and the Yale Children's Clinical Research Center.

For correspondence:Dr M Grey, Yale University School of Nursing, 100 Church Street South, PO Box 9740, New Haven, CT 06536-0740, USA. Fax +1 2037374480.

Abstract and commentary also published in Evidence-Based Nursing.

\section{Commentary}

Although the Diabetes Control and Complications Trial showed that improved glycaemic control delays the onset and slows the progression of severe microvascular complications of diabetes, ${ }^{1}$ improving glycaemic control remains a daunting problem for many people with type 1 diabetes mellitus. Often, the demanding lifestyle changes and rigorous self management behaviours are difficult to implement. In the first well designed randomised controlled trial that tests the effects of a behavioural intervention for adolescents receiving intensive diabetes treatment, the findings of Grey et al have important implications for the treatment of type 1 diabetes. They show that CST improves glycaemic outcomes and quality of life outcomes in adolescents, a group that often has difficulty reaching glycaemic goals.

This study shows the importance of teaching adolescents how to deal with the demands of a chronic illness. CST, a nurse taught intervention that incorporates behavioural strategies with coping skills and cognitive approaches, goes beyond simply offering support and knowledge. Adolescents learnt to deal with difficult situations, such as managing food decisions with friends, by role playing and observing the nurse model appropriate coping behaviours. This innovative approach is a valuable addition to diabetes treatment.

Because only a small number of adolescents from minority groups were studied, the effectiveness of CST for nonwhite adolescents is unclear. Although CST is designed for adolescents, the synergistic effect between CST and intensive treatment suggests that a similar behavioural approach should be developed and tested in adults with type 1 and type 2 diabetes, including those from non-white ethnic groups.

Grey et al describe CST as a relatively inexpensive, brief intervention. Although the actual costs of CST were not reported, intensive treatment, with its improvement in glycaemic control, leads to large healthcare cost savings over time through slowed progression of complications. ${ }^{2}$ Detailed investigation into the further cost savings realised by CST, if any, may lead to wider use by healthcare organisations and providers.

Katie Weinger, RN, EdD Research Associate and Instructor Joslin Diabetes Center and Harvard Medical School Boston, Massachusetts, USA

1 The Diabetes Control and Complications Trial Research Group. The effect of intensive treatment of diabetes on the development and progression of long-term complications in insulindependent diabetes mellitus. $N$ Engl I Med 1993;329:977-86.

2 The Diabetes Control and Complications Trial Research Group. Lifetime benefits and costs of intensive therapy as practiced in the diabetes control and complications trial. JAMA 1996; 276:1409-15. 